\title{
RECONSTRUCTING POWERFUL KNOWLEDGE IN AN ERA OF CLIMATE CHANGE
}

\author{
Andrew Kirby (https://orcid.org/0000-0001-5252-2220)* \\ School of Social and Behavioral Science, Arizona State University, PO Box 37100, Phoenix AZ 85069-7100, USA \\ *akirby@asu.edu
}

\section{Submitted: 02/01/2020. Accepted: 30/01/2020 Published: 31/01/2020}

\begin{abstract}
Purpose: Identifies a hierarchy of information and argues that professional knowledge has marginalized 'local knowledge'.

Methodology/Approach: In a review of recent research, the paper offers examples of how 'wicked problems' (from obesity to climate change) impose different burdens on different communities, which foregrounds the value of residents' experiences.

Findings: In an era of climate change, adaptive planning must incorporate 'local knowledge', which may return to older technologies and established practices.

Research Implication: The paper argues that 'local knowledge' can be 'powerful knowledge', as discussed within educational research, which has important implications for school and college curricula.

Originality/Value of paper: Amateur experts, citizen observatories and crowd sourced data can all play significant roles within communities facing new forms of risk and hazard.
\end{abstract}

KEYWORD: science, policy, locality, climate, adaptation.

\section{RECONSTRUINDO CONHECIMENTOS PODEROSOS EM UMA ERA DE MUDANÇAS CLIMÁTICAS}

\section{RESUMO}

Objetivo: identifica uma hierarquia de informações e argumenta que os profissionais do conhecimento marginalizaram o 'conhecimento local'.

Metodologia: em uma revisão de pesquisa recente, o artigo oferece exemplos de como os 'problemas perversos' (da obesidade às mudanças climáticas) impõem encargos diferentes à diferentes comunidades, o que enfatiza o valor das experiências dos residentes.

Constatações: Em uma era de mudanças climáticas, o planejamento adaptativo deve incorporar 'conhecimento local', que pode retornar às tecnologias mais antigas e às práticas estabelecidas.

Limitação / implicação da pesquisa: o artigo argumenta que o 'conhecimento local' pode ser um 'conhecimento poderoso', conforme discutido na pesquisa educacional, que tem implicações importantes para os currículos das escolas e faculdades.

Originalidade / valor do trabalho: especialistas amadores, observatórios de cidadãos e dados de multidões podem desempenhar papéis significativos nas comunidades que enfrentam novas formas de risco e periculosidade.

PALAVRAS CHAVE: ciência, política, localidade, clima, adaptação. 


\section{INTRODUCTION}

This paper is motivated by the existence of what Durkheim saw as 'powerful knowledge', a concept under discussion in current educational circles (Young and Muller, 2013). Although it is a cliché to state that knowledge is power, it remains unclear just what kinds of knowledge are the most powerful. While there exist an infinite number of paths to knowledge (each of which involves different content), modernity has dictated a basic consensus on the purposes of education and what it should include. As Parker observes, "This is the curriculum-these are the school subjects. The matter is settled, and settled, more or less, around the world" (Parker, 2016).

This paper develops the argument that such consensus may be the inevitable outcome of a globalizing economy which displays little tolerance for indigenous skills; more positively, it might also arise from the steady creation of a global society based upon our willingness to comprehend each other through shared forms of expression. These are, though, post-hoc rationalizations of what have been massive changes occurring throughout the $20^{\text {th }}$ and $21^{\text {st }}$ centuries within the market, culture and other social and political structures (Rossi, 2017).

In this new millennium, the challenges facing the individual are no longer limited to those facing the first humans-hunger, housing, health. In addition, we have produced entirely new problems, immediate by-products of the complex urban societies that we have created. In finding ways to feed 7.5 billion people, for example, we have disrupted the traditional relationships between people and food. One result is that one billion people are malnourished, while one billion are obese. It is a grotesque reality that those who are hungry could be relatively simply fed with the vast amounts of food that are unharvested, rejected for aesthetic reasons or wasted-a relatively simple logistic challenge. It is an even greater paradox that the global obesity pandemic (and its outcome, pediatric diabetes) presents the far larger public health challenge (NCD, 2016).

Obesity is one of a group of threats that are commonly identified as "wicked problems". These are challenges that transcend the boundaries of more traditional public problems, such as smoking or malaria. Kreuter et al. summarize the differences between 'tame' and 'wicked' problems in four ways. First is the complexity of problem definition. Although the incidence of drug use - to take one example - may be high, there often exists no consensus on whether this is un/acceptable behavior. This is a function of the second factor, namely the multiplicity of stakeholders in an era when expert opinion is not dominant. This translates in turn to the third issue, namely that accepted scientific protocols compete for control of the problem with skeptics, as we see in the context of vaccination. Fourth, this leads to confusion concerning when to cease problem intervention, the indeterminacy of any form of 'stopping rule' (Kreuter et al., 2004).

There exist various critiques of 'wickedness' especially those which are situated within the policy sciences, which reject the claim that there exist problems which are not amenable to analysis and resolution (Turnbull and Hoppe, 2019) Critics also point to the importance of dismantling grand challenges and re-constituting them as a mosaic of local challenges, a point to which we will return below (Noordegraaf et al., 2019). However, in large measure these represent the response of policy professionals and as such constitute a turf war, which is not immediately relevant to this discussion. That said, the use of the term 'wicked' comes with its own problems, not least of which is the intimation that some challenges are benign, while others are in some way malevolent. Because of the way in which this can constitute a distraction, in the remainder of this paper the term 'wicked" is jettisoned, and instead the more evocative term 'twisted' is employed (from the Spanish phrase 'problemas retorcidos').

Twisted problems are not restricted to social contexts. The human relation to nature is a foundational dimension of how societies evolve, and as nature is never static, so the challenge to human activity is continual. This is the case with seismic activity, forest fires and floods. As climate changes continually, successful communities monitor the environment in which they exist and act accordingly. Rather than hoping that national and international policies on energy use will lead to different climate outcomes, well-adapted local communities develop sophisticated strategies to 
produce best outcomes from already-changing circumstances. The range of policy options is vast, and depends upon the morphology and demographics of the community on the one hand and the changes occurring within nature on the other. Cities may need to develop strategies linked to increased rainfall amounts, increased drought, or increased weather unpredictability. Triage may be necessary, pulling back development from peripheral locations increasingly threatened by fires, or, elsewhere, by rising sea levels. And in some instances, communities may fail to adapt and will disappear, as has happened in many European locations (due to changed coastlines, for instance).

This paper explores the challenges posed by the twisted problem of climate change and adaptive responses. Drawing on published sources, it does the following: in the next section, it explores the weaknesses of conventional science in this context; the paucity of individual disciplines; and the transition to interdisciplinarity and transdisciplinarity. This is followed by an examination of adaptive responses and in particular the role of local knowledge in creating successful policy. In the subsequent section, the paper explores what this means for our assumptions about powerful knowledge, concluding with some auto-criticism of the arguments developed here in the context of further research.

\section{SCIENCE AND THE INTERDISCIPLINARITY AND TRANSDISCIPLINARITY}

\subsection{Science and its limits}

In the early $20^{\text {th }}$ century, the production of knowledge was often based upon the needs of the evolving nation, which in turn was shaped by the bureaucratic drive of the state apparatus towards standardization and control. Both tendencies involved an emphasis on conformity and uniform outcomes, with the result that national norms were paramount - another way in which the taken-for granted curriculum (noted by Parker, 2016), was fostered. Standardization in the workplace and the classroom (which can be also viewed as an educational workplace: Latour and Woolgar, 1986) both promote the primacy of science and technology. These STEM fields appear unsusceptible to national or ideological contexts and in consequence are often seen to possess greater elegance than other disciplines: this is deemed to be "high epistemic quality" (e.g. Hudson et al. 2015).

Despite its historic standing as a high-status academic activity (with, for instance, the largest number of Nobel prizes offered for its advancement), it is hard to see exactly why science continues to be held in this regard. Sarewitz, for example, points to a current crisis (2016, p.5):

Science, pride of modernity, our one source of objective knowledge, is in deep trouble. Stoked by fifty years of growing public investments, scientists are more productive than ever, pouring out millions of articles in thousands of journals covering an everexpanding array of fields and phenomena. But much of this supposed knowledge is turning out to be contestable, unreliable, unusable, or flat-out wrong.

Sarewitz provides a chilling analysis of what has unraveled since 1945, due in large measure to the distortions caused by state funding, especially for the very broad range of research activities that are linked to national security.

The most problematic aspect of scientific practice rests on claims to objectivity and - via the application of 'the scientific method' - correctness. Truth is validated through publication, although the classic model of peer review is widely regarded as damaged, if not actually broken (Biagioli, 2002). An obvious instance is found in the context of climate change. We are now used to reading of probabilistic statements about the degree of consensus among scientists on anthropomorphic climate change; yet it is hard to understand how the predictive capacity of simulation models can be tested and therefore objectively assessed. It is for reasons such as this that Sarewitz argues that: "from metastatic cancer to climate change to growth economics to dietary standards, science that is supposed to yield clarity and solutions is in many instances leading instead to contradiction, controversy, and confusion" (2016. p.5). 
Individual sciences are, in summary, proving to be weak in their response to contemporary challenges. Researchers accustomed to working on narrow problems tend to have limited abilities when it comes to confronting twisted problems which, as we have seen, have few precedents and permit even less agreement on problem definition. Behavioral economists, for instance, have been vocal in advocating for economic interventions to push back against obesity, arguing that price increases for sugar additives in food and drink must, through price elasticity, reduce consumption. So-called Junk Food Taxes have been tried in several countries, but after initial 'sticker shock' (causing consumption to fall temporarily), substitutions have followed; this is especially true for the lowest-income consumers, who purchase the highest quantities of highly sugared items and who tend to have the highest incidence of overweight. (Cornelsen et al., 2015). This is merely a single example of why multidisciplinary teams are increasingly assembled to tackle public health challenges.

\subsection{Disciplines, science, twisted problems}

The sociology of education may be progressive, insofar as its practitioners believe that education can offer emancipatory results, and that the right forms of education 'maketh men free', as Marx might have asserted. It is however often deeply conservative in the way in which knowledge is valorized in very hierarchical terms, with the greatest approbation reserved for scientific disciplines and the least value attached to local knowledge, the products of everyday life (e.g. Young and Muller, 2013).

In the context of powerful knowledge, science is the highest status academic work (with the highest epistemic quality) and, it is argued, must be available to all students and not reserved only for the best schools and colleges (Nash, 2010, p.201). If, though, we view scientific disciplines more skeptically, then this calculation changes. Further, if twisted problems demand more complex public responses, then different approaches to knowledge are required. This can come about in two ways: first, individual disciplines are likely to be less adequate to the tasks confronting us than multiple disciplines, and second, high status forms of knowledge may need to be paired with other forms of insight, as is promoted in transdisciplinary approaches (Kirby, 2019a).

\subsubsection{Disciplines and Multiple Disciplinarity.}

Implicit to the continued existence of twisted problems is that traditional forms of research have proved to be inadequate to the task of finding explanations and therefore solutions. Obesity has already been mentioned as a public health challenge that does not fall into simple analytical categories. While it exists as a medical problem facing individuals, it is also manifested as a group phenomenon (which has attracted the attention of anthropologists), while the production of food has been researched by geographers and sociologists. None of these offers a singular explanation of why overweight is so prevalent as a global outcome; explanations and public health strategies will inevitably depend upon research teams drawn from different disciplines (Lang and Rayner, 2006).

The emphasis upon different forms of team research can be seen as a direct outcome of more complex research challenges. The most elaborate of these team approaches is transdisciplinarity, which is both a mix of disciplinary research plus the input of what are usually termed 'stakeholders'. These are lay persons with some stake in the research, who may also be 'knowledgeholders' - that is to say, in possession of some direct experience of the problem under review (Kirby, 2019a).

\subsubsection{Formal and informal research.}

Once we move beyond the primacy of specific disciplines, it is easier to incorporate other forms of knowledge into a research team. For example, if we are examining the relation between 
food and health, it is likely that the history of cultivation in a specific location will be valuable, and this may in turn involve non-academic resources, such as tribal lore, historical archives, or neighborhood experiences with community gardening. In addition, and as we will show below, the involvement of such stakeholders in the research process opens up exciting possibilities for how the school and college curriculum might evolve in the shadow of contemporary problems.

\subsection{Different forms of Knowledge}

The recognition of twisted problems as threats to a society's quality of life-perhaps existential threats to a community's survival-take us beyond the elegant abstractions of Enlightenment thought to bodies of useable knowledge. This is not new, of course. Research has been appropriated in many ways before: aspects of psychological research were stolen by the nascent advertising industry and turned into a successful form of manipulation for commercial purposes (Goffman, 1979). In this paper, the thought experiment involves a more aspirational outcome, namely the creation of knowledge whose power lies in the potential to improve lives. Again, this is hardly a new intent. Attempts have been made to teach citizenship, environmental awareness, human rights and sustainability on the grounds that these are 'improving'. Parker, for instance discusses the cosmopolitan benefits of creating an international curriculum (2016).

Here, however, we are reversing the process, in that we do not delineate the desirable content (such as the historical example of teaching home economics in order to create a supposedly harmonious domestic economy with structured gender roles); instead, we have identified the existence of public problems and the need for knowledge that can sustain the creation of solutions. As touched upon already, this will be transdisciplinary by necessity, and will therefore introduce forms of 'local knowledge' (Geertz, 1973). Transdisciplinarity demands the input of knowledgeholders, whose expertise is context-specific. To take a current example, any team seeking to understand the public health crisis among members of the Navajo Nation (where obesity is endemic) must involve geneticists but must also draw on local experiences about supplies of junk food on the one hand, and the potential of heritage seeds on the other (Ornelas et al. 2017).

One of the strengths of this configuration is that it necessarily changes how we view different modes of thought within the school and college curriculum. Formal knowledge, integrated vertically from school to doctorate, is re-united with horizontal knowledge held within the home and local institutions (Bernstein, 1999). A move away from a discipline-heavy curriculum constitutes an inevitable move away from a universal curriculum (of the sort associated with Bourdieu), and brings us, with equal inevitability, to a curriculum of greater nuance.

\section{THE CLIMATE CHALLENGE}

\subsection{Knowledge and Adaptation}

The most pressing example of a 'twisted problem' is that of climate change. It may in fact deserve the term 'wicked' insofar as we know of no way forward which is guaranteed to reverse the current warming trends; in addition, the energy industry strongly rejects the assertion that climate change is anthropomorphic. Therefore, until energy production is fully restructured, the most realistic approach to policy development is the creation of adaptive strategies. These may take various forms. The simplest are coping strategies developed by individual households, which may involve redesigning a home (e.g. limiting flammable materials, in regions subject to fires) or even the way a dwelling is used (e.g. relegating lower floors, which may be flooded, for occasional use).

In more structured contexts, local governments may introduce cash or tax incentives to encourage households to undertake such redesigns or, in some cases, even to move (for instance the Bogota Humana project in Colombia: Sarmiento, 2018). If these strategies fail, compulsion is also 
an option in many societies: in the Netherlands, for instance, complex land-use protocols underly the country's flood control strategies. In many cities in the Global North, existing land-use plans are being changed and zoning rules altered, while infrastructure changes are designed to keep out floodwaters, to direct overflow, or to use floodwaters to offset groundwater depletion. In extreme cases, municipalities may rebuild after a disaster with new technologies (such as the green reconstruction of Greensburg, KS following its destruction by a tornado: Sparks and White, 2013); in even rarer cases, municipalities can attempt to move entire communities, as is being discussed currently in Indonesia.

There is certainly a burgeoning literature on climate adaptation but it has several limitations. Crucially, it conflates the creation of managerial positions in sustainability within municipalities with effective policy development, and the development of policy with successful outcomes (Kirby, $2019 \mathrm{~b}$ ). As is however clear, the development of such outcomes will depend upon much more than the creation of professional career paths linked to sustainability or related fields. This is because of the twisted nature of adaptive challenges, which are different from many other urban problems. While transport plans - to take one example - are designed for each municipality, they also depend upon a relatively small set of modal choices and technological possibilities. This is not the case in the context of climate change adaptation. Any municipality may be faced by a complex mixture of challenges and, subsequently, cascading problems such as drought, vegetation loss, fires, increased run off and then flooding, to take a common example from California (Davis, 1998). Elsewhere, coastal communities confront sea-level rise, while those who live in river valleys can face longer and more intense flood seasons. To respond to this level of complexity, it is important to move outside the roster of professionals associated with emergency planning in order to incorporate an array of skills; doing so widens the net of experience and in turn the policy possibilities (Olazabal et al. 2018).

Nor of course are threats limited to natural events. The latter can generate second-order risks which constitute in turn a new level of threat: this has been identified as a new 'exposome' (Wild, 2012). The most dramatic example of recent decades was the failure of a series of 'fail-safe' technologies at the Fukushima Daiichi nuclear plant following the 2011 tsunami. The floodingwhich caused over 20,000 deaths - also resulted in the closure of the plant and evacuation, which has been linked to many subsequent deaths (Hasegawa et al. 2016).

The creation of effective adaptive plans - that is, plans which reduce the impacts of hazards short of permanent evacuation - is therefore a complex process. Unusually violent storm activity for instance may - or may not - be predicted via conventional simulation models (Sillmann et al. 2017). More crucially, even when solid predictions of risks exist, interpretations of their significance can vary greatly. In part, this is a function of professional norms and in part related to factors such as the time frame within which deliberations are placed. A particularly good example is presented by Yarnal and colleagues in a study of a coastal community in Florida; focus groups of different professionals generated entirely different-and conflicting-proposals for adaptive responses to imminent sea level rise. Some proposals could easily be interpreted as actually increasing the risks facing the community (Frazier et al., 2010).

It is in these contexts that what Geertz called 'local knowledge' is of fundamental importance (1983). In many localities, there exists a reservoir of wisdom which has coalesced across generations. A very simple example is that in arid and semi-arid environments it is inadvisable to place oneself in a wash or gully which can fill rapidly, even from storms a distance away. Tourists may learn this the hard way and residents may find their new homes to be less than secure.

This general principle dictates that some locations are safer than others, which is reinforced by a process of trial and error over the long process of establishing a settlement. A city such as Houston TX developed very slowly in some areas as locals knew that slow-draining run-off could easily lead to flooding: any homes unwisely built in these flood plains would be at risk. However, 
over time, events conspired to marginalize this local wisdom. Large national and international construction companies discounted the threats, especially as Federal flood insurance reassured prospective purchasers. Many of these new residents had no prior knowledge of the area. Nor could they be aware of the potential of more active storms in the new era. The convergence of these factors contributed to the results of Hurricane Harvey, which dumped in excess of $127 \mathrm{cms}$. of rain on the city and caused evacuation of tens of thousands of residents, many from relatively newlydeveloped suburbs. It is estimated that over $\$ 16$ billion in damage occurred (City of Houston, 2019).

Key to understanding the value of local knowledge is the recognition that many locations have seen some form of continuous occupation that may stretch back to indigenous settlers. The latter were especially sensitive to natural conditions and-without modern palliatives such as insurance support or emergency managers - would abandon settlements where the risk calculus was no longer in their favor. The Southwestern US, for instance, is marked by numerous sites that were abandoned during an early period of climate change. Today, however, land use is not based solely upon risk-averse decisions. In many cities, especially in the Global South, low-income residents push into more marginal locations - on slopes, on fault lines, in areas prone to floods-simply because they can discount the costs of shelter there. This exposes these residents to high levels of risk which are often exacerbated by poorly funded emergency providers and few welfare services (Pielke et al. 2007).

\subsection{What Wisdom means for Knowledge}

When unusual circumstances demand it, it may be necessary to search for forms of knowledge which do not conform to norms commonly used within the professions, such as planning. This may be especially true in cases of climate change where many communities may be returning to previous eras in terms of environmental risks and hazards.

An example of this can be found in the contemporary use of aljibes, cisterns found extensively in agricultural districts throughout Spain and Portugal; these are modeled on Moorish designs introduced in the $8^{\text {th }}$ century (although based in turn on technologies that reach back to Neolithic designs found throughout the Mediterranean: Blanco et al. 2007). Aljibes constituted a passive form of water harvesting, storing runoff beneath ground level and using the water as needed for irrigation or domestic purposes. This principle has been reapplied in the construction of flood controls in Spanish cities such as Alicante, where holding ponds atop cisterns have been constructed to limit runoff and then hold it as greywater for later use. A byproduct is the construction of biodiverse habitats within the city. We can see this as an example of local knowledge or a form of culturally-informed wisdom whose roots are especially deep (Hernández and Morote, 2019).

Alicante is a striking example of re-incorporating traditional knowledge into contemporary planning. While water in Spain has been subject to interventionist national plans since 2001, regions such as Valencia and Murcia have moved in the opposite direction by integrating reduced demand and alternative supply. It is argued that "Despite being the most arid region in Spain and with a natural scarcity of water, the endeavors undertaken in this territory make it one of the best adapted to water scarcity" (Morote et al. 2019).

Practical knowledge does not though necessarily depend upon historical experiences. In addition to cultural memory, residents in urban neighborhoods harness their own observations about risks and remedies. Chiang shows that Taiwanese residents are aware of flood risks and flood events in detail, being able to distinguish different levels of risk from street to street. This can then connect to adaptive responses. Some are relatively simple, such as reorganizing the household above flood levels. Interestingly, awareness is not a function of proximity or even longevity of residence but seems to be linked to social capital, and it is this which appears to determine whether residents do or do not take action (Chiang, 2018). 


\subsection{Amateur Experts and Citizen Science}

The recognition that residents have both a stake in, and knowledge of, their communities has led to a burgeoning academic and policy interest in incorporating these attributes. This has been manifested in terms of efforts to increase what was long termed 'public participation' and which led, for instance, to the development of participative methodologies such as PhotoVoice. In this, residents were, for example, given cameras and a stipend to photograph things in their neighborhood which dis/pleased them, in order to identify how local government should intervene (Wang et al. 2004).

More open-ended projects can involve residents who participate in data collection exercises, related to environmental crises such as species loss (Gura, 2013). The terms 'amateur expert' and 'citizen scientist' are common, although these clearly constitute attempts to co-opt the so-called 'lay-public' into ongoing empirical research projects, even as unpaid labor. It is in the context of adaptation that we see this potential come to fruition. Discussing the example of Houston TX and Hurricane Harvey once more, recent research shows how 'citizen GIS' is able to shed light on the details of where flooding occurred with much greater specificity than other analyses (Yang et al., 2019). The researchers offer fascinating insights into how these data were crowdsourced and conclude "Given the above analyses, we found citizen science data could provide information that was not identified by remotely sensed data, especially in residential and commercial lands, and inside the city center. These contributions indicate that citizen science data could help to increase data integrity" $(2019$, p.7).

Central to the argument being offered here is that there must be reciprocity between professionals and residents. The former must have some interest in the accumulated experiences of the latter; equally, there must be some acknowledgement of professional values. This is being increasingly tested in the 'new normal' of climate change, as emergency managers demand that residents follow instructions to prepare for trouble, to evacuate in the face of hazards and in some instances to leave a neighborhood for good.

There appear to be different strategies emerging in the US. Following the catastrophe of Hurricane Katrina in 2005, in which affluent Anglo residents fled New Orleans but many poor African Americans stayed and faced unimaginable privations - while hundreds drowned - there has been an increased tendency to try to force residents to evacuate ahead of high-risk events such as hurricanes. In large measure this is connected to the militarization of risk, with emergency management being increasingly linked to concepts of homeland security. This results in entirely natural hazards being bundled with threats of terrorism or industrial accidents (Lundberg and Willis, 2015). In municipalities where this is the case, professional experience is linked to control via law enforcement, and so instructions pass only from expert to resident.

This sits uneasily with the alternative approach to risk identified as resilience planning. The concept of resilience is of interest within several disciplines (including psychology and gerontology) and high-profile efforts are underway to create 'resilient cities' (Kirby, 2019b). While this seems to be a nuanced approach to adaptation, there exists a critique which sees resilience planning as a form of triage, in which risks are merely contained. In cities, this can mean that disaster impacts are channeled to neighborhoods with low-cost assets, and resilient cities may become increasingly unequal cities. These are, in other words, strategies steeped in elite professional values, and perhaps most applicable in airports or following terror attacks. They involve few nods to adaptation. More successful approaches are proactive, participative and practical. An interesting example is that of Charlotte NC, where local stakeholders designed a stormwater utility district, charged with using GIS to identify flood risks within the community and to use local funds to buy out properties, thereby saving the money then being spent to recover after frequent floods (Patterson, 2017). This proactive approach is very different from the ways in which Federal funds are used inefficiently after the fact to compensate residents for their losses. 


\section{DISCUSSION}

\subsection{Refiguring Powerful Knowledge}

This discussion of local knowledge cannot be exhaustive because there are so many possible examples of communities that are confronting climate change, and which will have to draw upon their own resources of experience in order to navigate through the challenges of the coming decades. Implicit in this re-evaluation of scientific knowledge and the incorporation of local knowledge is a restructuring of the local state, the locus of municipal decision-making. For civil society to aspire to insert itself into the processes of professional decision-making and, frequently, to challenge the goals of the market, involves a re-calibration of the relations between these three institutions. The goals of many economic interests tend to diverge from a coherent response to climate change, in large measure because profit-taking can be taken up until the moment that environmental conditions become intolerable. For instance, it is now widely understood that Florida is facing a triple threat from land subsidence (due to groundwater depletion), inundation from higher sea levels, and more active storm patterns. Despite this, population growth and real estate demand remain high and are being met by large construction corporations. The contradiction between the processes of growth under conditions of increased risk is resolved by what has been termed 'climate gentrification', which is to say that new construction is being directed to higher elevations, while prices slide in lower neighborhoods (McAlpine and Porter, 2018). Again, this reinforces existing inequalities.

The likelihood that civil society will easily insinuate itself into the management of sustainability planning is equally problematic. As already noted, dealing with risk - an immanent condition-is often treated instead as emergency management once a disaster event has begun. Linking emergency with homeland security effectively excludes stakeholders other than as residents to be managed or as victims to be rescued. Rebranding emergency management as adaptive planning, which can incorporate multiple knowledge holders will involve a recalibration of a profession and of the goals of many local states (Kirby, 2019b). Even less well understood is the recognition that involving knowledge-holders depends upon a number of pre-conditions which themselves offer insights into the way in which the local state operates. A study by Wehn et al. (2015) of flood management protocols in three European municipalities shows that citizen observatories operate in entirely different ways, with, perhaps most surprisingly, the situation in the Netherlands suggesting minimal citizen involvement.

\subsection{The Limits to Local Knowledge}

This thought experiment must invite some critical commentary. This might include the following considerations.

\subsubsection{The limits of instrumentalism.}

Education that embraces a societal goal may be in danger of becoming subsidiary to that goal. There was evidence of this at the start of the $20^{\text {th }}$ century, when disciplines were in thrall to the creation and maintenance of Empire (Godlewska and Smith, 1994). This tendency was manifested most sharply under National Socialism and Soviet realism, where knowledge was manipulated and suppressed according to the demands of the state (Atkinson and Dodds, 2002,). Naively, it is possible to make the counter case-that instrumentalism in the service of a progressive goal is no bad thing. Nonetheless, the critique of ways in which indigenous knowledge continues to be ignored, even within the academy, shows that this is a complex challenge (Castleden et al., 2015). 


\subsubsection{A retreat from abstract knowledge.}

The identification of research goals by funding agencies can certainly elevate concern for practical topics (e.g. breast cancer research) at the expense of theory (most contemporary physics or linguistics). It would, though, be hard to argue that this preference for empiricism has completely distorted the academy: Hawking is one of the most frequently cited physical scientists; Bourdieu and Foucault have been cited well in excess of a million times: these are not empiricists.

\subsubsection{The primacy of locality.}

Recognizing the validity of context does not necessarily mean that everything must be filtered through the concerns of the specific locality. There may be a temptation to reduce every curriculum to its immediate environment, a point noted by Young and Lambert discussing a high school teacher (2014, p. 184): "I cannot teach glaciation to my pupils (in Whitechapel [East London, UK]) because they will never encounter it. It is nothing to do with their lives and they do not see the relevance". This is simply poor pedagogy. Recognizing the existence of local knowledge does not demand that it envelop everything, in the same way that it does not signal a retreat from abstract knowledge.

\subsubsection{Incorporating local knowledge is hard work.}

This argument might appear to suggest that re-incorporating local and/or indigenous views is akin to any research methodology or innovation in a curriculum, introducing modules on sustainability for instance. Of course, it is much more challenging. The gulf separating of the academy from the community (that is, those who finance it) can still surprise. Adger and colleagues, for instance, appear to distinguish subjective and scientific knowledge, while equating the former with inertia and a propensity not to adapt (Adger et al., 2009). In an otherwise thoughtful assessment of adaptive interventions, Vogel et al. seem to opt for a similar position: "in the case of natural disasters, lay people frequently view such events as "acts of God" and thus also not amenable to personal or policy intervention. Once an immediate threat is averted or past and "normal life" reestablished, both the periodic extremes and the gradual long-term changes get placed far below the more pressing daily concerns" (Vogel et al., 2007). Clearly, portraying belief not only as anti-science but as irrational is not a firm foundation for trust and understanding between different actors.

\subsubsection{Resilience and austerity.}

It is possible to make a connection between local knowledge and the increased visibility of 'resilience' as both a concept and a policy goal. In the former case, as we have seen, the status of the resident is elevated vis-à-vis the professional. In the second, there is an increased emphasis upon professionals finding ways to make residents 'resilient' in the face of risk, hazard and actual disaster. Yet elevating the role played by individuals and communities can be highly regressive. Echoing Marcuse, we might ask "resilient for whom?" Just as inequality can be sustainable, so communities living in poverty can be resilient. We must be wary of promoting resilience in the context of austerity politics which withdraw municipal support from neighborhoods because they are 'resilient' (Fernández, Manuel-Navarrete and Torres-Salinas, 2016).

\section{CONCLUSIONS}

This paper has offered an exploration of the concept of 'powerful knowledge', using recent developments in adaptive planning as a context. Educational researchers have argued persuasively 
for increased access to 'vertical knowledge', in order that individuals are not restricted in their life choices, which can be constrained by a focus on 'horizontal knowledge'. It is indeed the case that individuals must have the widest choices in the knowledge they can access. Class, age and gender should not define the educational opportunities open to any individual, any household or any community. Nonetheless, this emphasis upon access for the individual makes, in turn, numerous assumptions about professional forms of knowledge, and especially the primacy of scientific reasoning in contrast to 'local knowledge'.

Here, the argument has been developed that as we-as members of urban societies-move into a new era of climate change, we are placed in a potentially new exposome. Accepted norms within the natural environment are subject to change, perhaps of a catastrophic extent in some locations. This means that accepted forms of scientific and professional analysis are likely to be inadequate. Universal norms and value can be of minimal value in decoding the unique mix of threats and solutions that exist within neighborhoods, cities and regions.

For these reasons, this paper advocates a new approach to the concept of powerful knowledge, one that incorporates wisdom as a valued asset within education and community life. As we have seen, a growing number of technological innovations can link up with older standards of local knowledge to produce valuable outcomes, generated by residents rather than solely by professionals. Amateur experts, citizen observatories and crowdsourced data can all play significant roles within communities facing new forms of risk and hazard.

This trend is not entirely novel. Transdisciplinary research has been promoted in recent decades, especially within European academe. However, it has tended to be project based and the research has tended to be of benefit to researchers rather than communities. Here, the focus is upon a broadening of how we value knowledge-holders within our communities. Their knowledge is indeed powerful and should be respected as such.

\section{REFERENCES}

Adger, W.N., Dessai, S., Goulden, M., Hulme, M., Lorenzoni, I., Nelson, D.R., Naess, L.O., Wolf, J. and Wreford, A. (2009). Are there social limits to adaptation to climate change? Climatic change, 93(3-4), 335-354. https://doi.org/10.1007/s10584-008-9520-z

Atkinson, D. and Dodds, K. (2002). Geopolitical traditions: Critical histories of a century of geopolitical thought. Routledge.

Bernstein, B. (1999). Vertical and horizontal discourse: an essay. British Journal of Sociology of Education, 20(2), 157173.

Biagioli M. (2002). From book censorship to academic peer review. Emergences: Journal for the Study of Media \& Composite Cultures, 12(1), 11-45. https://doi.org/10.1080/1045722022000003435

Blanco AG, Bermúdez FL, Boti AV. (2007). Los aljibes en la historia de la cultura: la realización en el Campo de Cartagena. Revista Murciana de Antropología. 2007(14), 441-78. https://doi.org/10.31644/ed.esp.2016.d02

Castleden, H., Sylvestre, P., Martin, D. and McNally, M. (2015). I Don't Think that Any Peer Review Committee... Would Ever 'Get'What I Currently Do: How Institutional Metrics for Success and Merit Risk Perpetuating the (Re) production of Colonial Relationships in Community-Based Participatory Research Involving Indigenous Peoples in Canada. International Indigenous Policy Journal, 6(4). https://doi.org/10.18584/iipj.2015.6.4.2

Chiang, Y.C. (2018). Exploring community risk perceptions of climate change-a case study of a flood-prone urban area of Taiwan. Cities, 74, 42-51. https://doi.org/10.1016/j.cities.2017.11.001

City of Houston. (2019). The Harvey Data Project https://www.houstontx.gov/postharvey/public/documents/3.2019havrvey-data-project.pdf accessed October16, 2019.

Cornelsen, L., Green, R., Dangour, A., \& Smith, R. (2015). Why fat taxes won't make us thin. Journal of Public Health, 37(1), 18-23. https://doi.org/10.1093/pubmed/fdu032

Davis, M. (1998). Ecology of fear: Los Angeles and the imagination of disaster. Macmillan. 
Fernández, I., Manuel-Navarrete, D. and Torres-Salinas, R. (2016). Breaking resilient patterns of inequality in Santiago de Chile: Challenges to navigate towards a more sustainable city. Sustainability, 8(8), 820. https://doi.org/10.3390/su8080820

Frazier, T.G., Wood, N., Yarnal, B. and Bauer, D.H. (2010). Influence of potential sea level rise on societal vulnerability to hurricane storm-surge hazards, Sarasota County, Florida. Applied Geography, 30(4), 490-505. https://doi.org/10.1016/j.apgeog.2010.05.005

Geertz, C. (1983). Local knowledge: Further essays in interpretive anthropology. Basic books.

Godlewska, A. and Smith, N. (1994). Geography and empire, Blackwell.

Goffman, E., (1979). Gender advertisements. New York, Harper Row.

Gura, T. (2013). Citizen science: amateur experts. Nature, 496(7444), 259-261. https://doi.org/10.1038/nj7444-259a

Hasegawa, A., Ohira, T., Maeda, M., Yasumura, S., \& Tanigawa, K. (2016). Emergency responses and health consequences after the Fukushima accident; evacuation and relocation. Clinical Oncology, 28(4), 237-244. https://doi.org/10.1016/j.clon.2016.01.002

Hernández M, Morote AF. (2019). The use of rainwater in Alicante (southeast Spain). A new urban approach to urban water management. Journal of Urban Planning, Landscape \& Environmental Design. 4(1), 53-66.

Hudson, B., Henderson, S and Hudson, A. (2015). Developing mathematical thinking in the primary classroom: liberating students and teachers as learners of mathematics, Journal of Curriculum Studies, 47(3), 374-398. https://doi.org/10.1080/00220272.2014.979233

Kirby, A. (2019b). Sustainability, Adaptation and the Local State: An Overview. Journal of Sustainability Research. 1:e190012. https://doi.org/10.20900/jsr20190012

Kirby, A., (2019a). Transdisciplinarity and sustainability science: A response to Sakao and Brambila-Macias in the context of sustainable cities research. Journal of cleaner production, 210, 238-245. https://doi.org/10.1016/j.jclepro.2018.11.003

Kreuter, M.W., De Rosa, C., Howze, E.H. and Baldwin, G.T. (2004). Understanding wicked problems: a key to advancing environmental health promotion. Health Education \& Behavior, 31(4), 441-454. https://doi.org/10.1177/1090198104265597

Lang, T. and Rayner, G. (2007). Overcoming policy cacophony on obesity: an ecological public health framework for policymakers. Obesity reviews, 8, 165-181. https://doi.org/10.1111/j.1467-789x.2007.00338.x

Latour, B. and Woolgar, S. (2013). Laboratory life: The construction of scientific facts. Princeton University Press.

Lundberg, R. and Willis, H. (2015). Assessing homeland security risks: A comparative risk assessment of 10 hazards. Homeland security affairs, 11(10).

McAlpine, S.A., Porter, J.R. (2018). Estimating Recent Local Impacts of Sea-Level Rise on Current Real-Estate Losses: A Housing Market Case Study in Miami-Dade, Florida'. Population Research Policy Review 37, $871-895$. https://doi.org/10.1007/s11113-018-9473-5

Morote ÁF, Olcina J, Hernández M. (2019). The use of non-conventional water resources as a means of adaptation to drought and climate change in Semi-Arid Regions: South-Eastern Spain. Water. 11(1), 93. https://doi.org/10.3390/w11010093

Nash, R., (2016). Explaining inequalities in school achievement: A realist analysis. Routledge

NCD Risk Factor Collaboration. (2016). Trends in adult body-mass index in 200 countries from 1975 to 2014: a pooled analysis of 1698 population-based measurement studies with 19.2 million participants. The Lancet, 387(10026), 13771396 https://doi.org/10.1016/S0140-6736(16)30054-X

Noordegraaf, M., Douglas, S., Geuijen K. and Van Der Steen, M. (2019). Weaknesses of wickedness: a critical perspective on wickedness theory. Policy and Society, 38(2), 278-297. https://doi.org/10.1080/14494035.2019.1617970

Norman, L.M., Caldeira, F., Callegary, J., Gray, F., O’Rourke, M.K., Meranza, V. and Van Rijn, S. (2012). Socioenvironmental health analysis in Nogales, Sonora, Mexico. Water Quality, Exposure and Health, 4(2), 79-91. https://doi.org/10.1007/s12403-012-0067-x

Olazabal, M., Chiabai, A., Foudi, S. and Neumann, M.B. (2018). Emergence of new knowledge for climate change adaptation. Environmental science \& policy, 83, 46-53. https://doi.org/10.1016/j.envsci.2018.01.017

Ornelas, I.J., Deschenie, D., Jim, J., Bishop, S., Lombard, K. and Beresford, S.A. (2017). Yéego Gardening!: A Community Garden Intervention to Promote Health on the Navajo Nation. Progress in community health partnerships: research, education, and action, 11(4), 417. https://doi.org/10.1353/cpr.2017.0049 
Parker, W.C. (2016). Towards A Powerful Human Rights Education in Schools: Problems and Possibilities' in James A Banks, ed., "Global Migration, Structural Inclusion, and Citizenship Education Across Nations".

Pielke Jr, R., Prins, G., Rayner, S. and Sarewitz, D. (2007). Climate change 2007: Lifting the taboo on adaptation. Nature, 445(7128), 597. https://doi.org/10.1038/445597a

Rossi, U. (2017). Cities and Global Capitalism Policy.

Sarewitz, D. (2016). Saving Science. The New Atlantis 5-40.

Sarmiento, H. (2018). Bogota Humana's climate resettlements: Displacement and the limits of the housing market in Colombia (Doctoral dissertation, UCLA).

Sillmann, J., Thorarinsdottir, T., Keenlyside, N., Schaller, N., Alexander, L.V., Hegerl, G., Seneviratne, S.I., Vautard, R., Zhang, X. and Zwiers, F.W. (2017). Understanding, modeling and predicting weather and climate extremes: Challenges and opportunities. Weather and climate extremes, 18, 65-74. https://doi.org/10.1016/j.wace.2017.10.003

Sparks L and White S.S. (2013). Going Green: the impacts of sustainability planning in Greensburg KS. International Journal of Sustainable Development and Planning, 8(3), 288-304. https://doi.org/10.2495/sdp-v8-n3-288-304

Turnbull, N. and Hoppe, R. (2019). Problematizing 'wickedness': a critique of the wicked problems concept, from philosophy to practice. Policy and Society, 38(2), 315-337. https://doi.org/10.1080/14494035.2018.1488796

Vogel, C., Moser, S.C., Kasperson, R.E. and Dabelko, G.D. (2007). Linking vulnerability, adaptation and resilience science to practice: Pathways, players and partnerships. Global environmental change. 17, 349-64. https://doi.org/10.1016/j.gloenvcha.2007.05.002

Wehn, U., Rusca, M., Evers, J. and Lanfranchi, V. (2015). Participation in flood risk management and the potential of citizen observatories: A governance analysis. Environmental Science \& Policy, 48, $225-236$. https://doi.org/10.1016/j.envsci.2014.12.017

Wild, C.P. (2012). The exposome: from concept to utility. International journal of epidemiology, 41(1), 24-32.

Yang, D., Yang, A., Qiu, H., Zhou, Y., Herrero, H., Fu, C.S., Yu, Q. and Tang, J. (2019). A Citizen-Contributed GIS Approach for Evaluating the Impacts of Land Use on Hurricane-Harvey-Induced Flooding in Houston Area. Land, 8. https://doi.org/10.3390/land8020025

Young, M. and Muller, J. (2013). On the powers of powerful knowledge. Review of education, 1(3), 229-250. https://doi.org/10.1002/rev3.3017

Young, M., Lambert, D., Roberts, C. and Roberts, M. (2014). Knowledge and the future school: Curriculum and social justice. Bloomsbury Publishing. 